\title{
The Transformation of Corrosion Products on Weathering Steel by Visible-Light Illumination under Simulated Marine Atmospheric Condition
}

\author{
Ping Qiu ${ }^{*}$, Zeshun Chen, Hongfei Yang, Lianjie Yang, Li Luo, Changfeng Chen \\ Beijing Key Laboratory of Failure, Corrosion and Protection of Oil/gas Facilities and department of \\ Materials Science and Engineering, China University of Petroleum, Beijing 102249, China \\ *E-mail: qiuping@ cup.edu.cn
}

doi: $10.20964 / 2016.12 .76$

Received: 17 August 2016 / Accepted: 13 October 2016 / Published: 10 November 2016

\begin{abstract}
This study has explored the visible-light illumination promoted corrosion behavior of weathering steel in simulated marine atmospheric condition. Open circuit potential measurements supplied a direct insight on this photovoltaic effect. To obtain better understanding on this process, the corresponding surface electronic properties together with its microstructures and chemical composition variations were characterized by Mott-Schottky analysis, AFM, XPS and confocal Raman microspectroscopy. All these combined results revealed that the rusted weathering steel sample collected in the dark displayed n-type photo-response due to the presence of hematite $\left(\alpha-\mathrm{Fe}_{2} \mathrm{O}_{3}\right)$, maghemite $\left(\gamma-\mathrm{Fe}_{2} \mathrm{O}_{3}\right)$, lepidocrocite $(\gamma-\mathrm{FeOOH})$ and goethite $(\alpha-\mathrm{FeOOH})$ on its surface. Whereas under illumination, the photogenerated electron-hole pair not only facilitated anodic dissolution and chloride ion adsorption but also leading to hematite to magnetite $\left(\mathrm{Fe}_{3} \mathrm{O}_{4}\right)$ transformation in the metal/corrosion layer interface.
\end{abstract}

Keywords: Atmospheric corrosion; Corrosion products; Visible-light illumination

\section{FULL TEXT}

(C) 2016 The Authors. Published by ESG (www.electrochemsci.org). This article is an open access article distributed under the terms and conditions of the Creative Commons Attribution license (http://creativecommons.org/licenses/by/4.0/). 